\title{
Future trends in mechatronics
}

\author{
Chiebuka T. Nnodim¹, Micheal O. Arowolo², Blessing D. Agboola ${ }^{3}$, Roseline O. Ogundokun ${ }^{4}$, Moses K. \\ Abiodun 5 \\ ${ }^{1}$ Department of Mechanical Engineering, Mechatronics Programme, Landmark University, Nigeria \\ 2, 4, 5 Department of Computer Science, Landmark University, Nigeria \\ ${ }^{3}$ Department of Civil Engineering, Landmark University, Nigeria
}

\begin{tabular}{l} 
Article Info \\
\hline Article history: \\
Received Aug 11, 2020 \\
Revised Oct 20, 2020 \\
Accepted Feb 12, 2021
\end{tabular}

\section{Keywords:}

Advanced mechatronic systems

Data science

Mechatronics

Miniaturization

Synergistic

\begin{abstract}
Presently, the move towards a more complex and multidisciplinary system development is increasingly important in order to understand and strengthen engineering approaches for the systems in the engineering field. This will lead to the effective and successful management of these systems. The scientific developments in computer engineering, simulation and modeling, electromechanical motion tools, power electronics, computers and informatics, micro-electro-mechanical systems (MEMS), microprocessors, and distributed system platforms (DSPs) have brought new challenges to industry and academia. Important aspects of designing advanced mechatronic products include modeling, simulation, analysis, virtual prototyping, and visualization. Competition on a global market includes the adaptation of new technology to produce better, cheaper, and smarter, scalable, multifunctional goods. Since the application area for developing such systems is very broad, including, for example, automotive, aeronautics, robotics or consumer products, and much more, there is also the need for flexible and adaptable methods to develop such systems. These dynamic interdisciplinary systems are called mechatronic systems, which refer to a system that possess synergistic integration of Software, electronic, and mechanical systems. To approach the complexity inherent in the aspects of the discipline, different methods and techniques of development and integration are coming from the disciplines involved. This paper will provide a brief review of the history, current developments and the future trends of mechatronics in general view.
\end{abstract}

This is an open access article under the $\underline{C C B Y-S A}$ license.

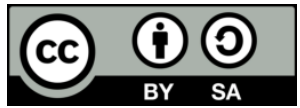

\section{Corresponding Author:}

Chiebuka T. Nnodim

Department of Mechanical Engineering, Mechatronic Programme

Landmark University

Km 4, Ipetu, PMB 1001, Omu-Aran, Kwara state, Nigeria

Email: nnodim.chiebuka@1mu.edu.ng

\section{INTRODUCTION}

Mechatronics is an interdisciplinary field which Harashima defines as "Mechanical and Synergistic Combination of Electrical engineering, computer science, and IT; That includes both the control and numerical systems methods used for developing integrated intelligence products" [1]. In this definition, synergistic effects are obviously targeted, which involve more than just adding the disciplines. Iserman et al. [2] describes Mechatronic as distinct from this concept as an interdisciplinary field, connecting mechanical systems, electronic systems, information technology and feed back control systems, where the mechanical system parts seem to be dominating the system's functions. Mechatronics is a methodology employed to optimize design for products made from electromechanics. The term Mechatronics was coined in 1969, when engineer Tetsuro Mori pulled together the 'Mechanical' and 'electronic' terms to describe the electronic 
control systems Yaskawa Electric Corp. was constructing for mechanical equipment from plant [3]. The most important thing in mechatronics is the integration and collaboration of different fields and disciplines (mechanical, electronic, computer) to achieve a robust synergistic system as shown in Figure 1.

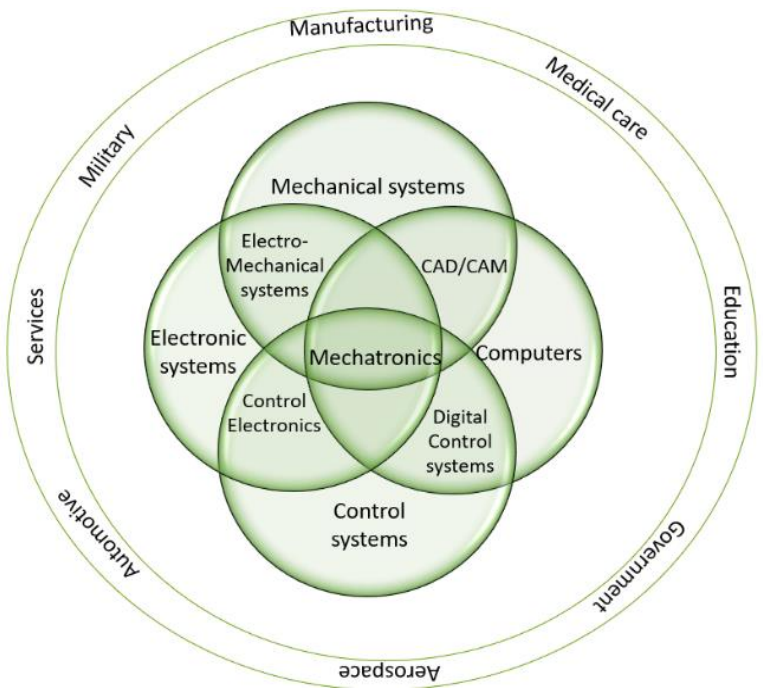

Figure 1. Interdisciplinary synergy

An essential feature of mechatronic systems and systems are their built-in intelligence, which comes from a synthesis of mechanical and electrical precision engineering and applied real time programming to the design process. The synergy can be created through the right mix of parameters, in other words, the final result should be more than just the amount of pieces thereof. The performance characteristics of mechatronic Products, should be one in which would have been difficult to achieve without interdisciplinary collaboration. Figure 2 shows the integrated design philosophy approach that yields mechatronics.

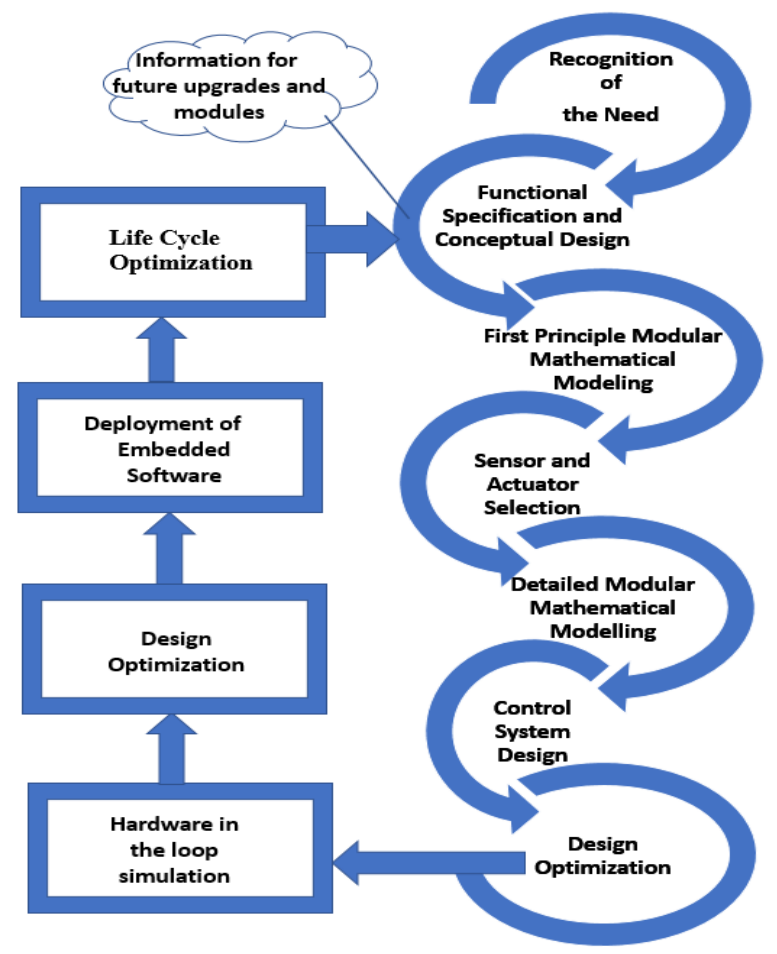

Figure 2. Mechatronics design philosophy 
Machine technology, such as machine tools, power turbines, aims to alleviate physical tension and stress on people, while electronics technology and information technology strive to alleviate human mental pressure. Within multidisciplinary engineering, machine technology along with electronics and information technology can replace the human element in both physical and mental efforts. In this sense, in order to evolve well-established autonomous systems in new products, the key driving force in mechatronic systems is the convergence of mainstream multidisciplinary technologies in engineering and computer science. Integrating mechanical systems and microelectronics opens up new possibilities for mechanical design and automated functions along with learning-based knowledge-based systems. Microcontrollers are increasingly embedded in electromechanical devices, creating much more flexibility in system design and control possibilities. The relationship between the internet of things (IoT) and mechatronics was analyzed by [4], and concluded that the future is still seen as requiring mechatronic thinking. The significance of this study is to show the trends and advances of mechatronics.

\section{DESIGN METHODOLOGY FOR MECHATRONIC SYSTEMS}

Mechatronics was first focused in the domain specifically back in the mid-1960's. Designing different resources and languages as well as with training. There are two ways in which engineers and companies go about designing a mechatronic system [5]. The first method resembles that of conventional mechanical architecture process discipline in engineering and is called Functional Modeling. The second approach is the model-based development, which more integrates with the Model-Based System Engineering 'MBSE' background. There are currently several attempts to standardize the methods used in the ModelBased Design approach, where the basis is to model languages and tools that can support the mechatronic system development process. Full modeling and Modeling approaches use both graphical models to represent the system specifications and thus identify issues early in the development process and minimize the system's time-to - market (TTM) growth. The basic differences between these methods are that functional modeling approaches are informal, and they are unable to deliver repeatable functional approach models of a specific product (the same product produced by two teams of engineers has a small chance of achieving the same results) where the Model-Based Design methodology is formalized and assisted with different modeling languages. Another big difference is the reuse of established design concepts as "Program Re-engineering" in model-based design. The issue with functional modeling is that the preserved design model can only be used for the same product model on which the model is centered. The archived design model can serve as a basis for product model development, specification, and exploration. There are four classes (classI to classIV) of mechatronic systems as classified by [6]. Several programming languagessuitable for mechatronic design, together with the suitable tools (MATLAB, Simscape, CAMel-view) for mechatronic design [6]. Figure 3 shows the conventional design methodology for mechatronic process.

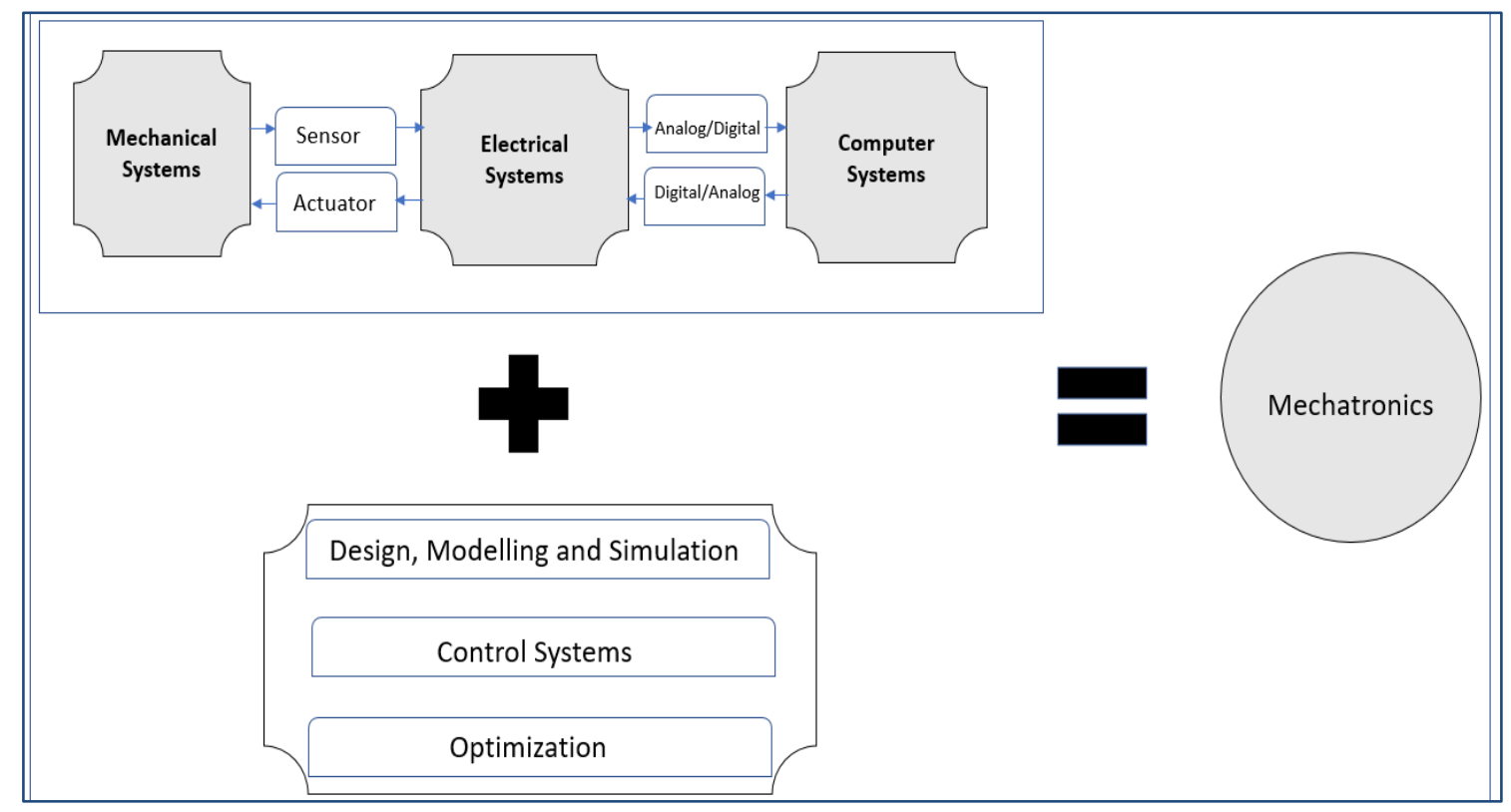

Figure 3. Mechatronics conventional design methodology 


\section{APPLICATIONS OF MECHATRONICS}

Human civilization and industrial technology have invented intelligent machines, high-tech devices, equipment, and products that improve the quality of life. Mechatronics allows the creation of smart machines that are self-conscious and that can make decisions. Companies now need hi-tech feedback to produce innovative and technology-enabled goods as their customers expect. Through seamlessly fusing mechanics and technology, the design and manufacture of items such as smartphones as well as futuristic vehicles are made possible. The use of mechatronics in advanced manufacturing has increased performance and product quality. The use of automated systems means you save time and the smooth use of streamlined procedures. Mass manufacturing had improved productivity and made cost-effective industrial production [7]. Technical errors are minimized as the use of intelligent sensors [8-11] and parameter controls ensures maintaining the planned operating conditions [11-13]. This technology has so much more to do than develop computercontrolled electromechanical systems. Mechatronics was originally seen as an assimilation of mechanics and electronics, but over the years, it is seen to include many more areas which include, telecommunication [1416], computer technology [17-19], systems engineering [20, 21], internet of things [22-24], civil engineering [25], instrumentation and control [26].

\section{EMERGING AND FUTURE TRENDS OF MECHATRONICS}

Over recent years, the complexity of devices and systems has increased dramatically, requiring a system-level approach to mechatronics design. This approach helps engineers to combine mechanical and control design, execute a test easily, and reuse algorithms within the final embedded delivery framework. This trend at system level is fueled by growing investments in the fields of medical, life sciences and renewable energy as well as developments in industrial machinery. This approach greatly improves the design process by combining best practices and technology available to streamline design, prototyping, and implementation. By splitting the design process into parallel threads, the engineers may introduce a more efficient process of creation. In the past a team has had to wait for a practical prototype to create a control algorithm for a mechanical device. Now engineers can use a virtual prototype based on concept models and simulation data to get started faster.

This approach, in addition to minimizing development time and its associated costs, allows for vibrant cooperation between design teams and provides feedback on system efficiency in early development phases. A full system digital model allows teams to mutually automate the overall structure, while increasing performance. Yet a good mechatronics design process includes built-in design instruments. Over the past few years device vendors have invested extensively in promoting this approach to design. Organizations such as National Instruments have developed interfaces to ensure smooth communication between the different devices. This helps engineers to build virtual implementations of their systems with a smooth path to embedded hardware and to reuse code and make the most of investments made in the phases of design and simulation. Algorithms need to be implemented on embedded hardware when prototyping and deploying. Engineers have a range of options for shortening production time during deployment. Which involve developing a component-level tailored control system to reduce costs and deploy on embedded commercialoff-the-shelf (COTS) systems [27]. The distinction between making a profit and suffering a loss is always to make the most reasonable decision based on such tradeoffs. "System ready" subsystems are mostly used for prototyping or as a delivery platform to check consumer acceptance before a cost-optimized custom design is designed.

In the last few years there has been a move towards customizable embedded platforms providing the simultaneous versatility of a custom configuration and rapid deployment associated with COTS hardware. National Instruments launched the RIO (reconfigurable I/O) platform some seven years ago. Using the graphical development platform NI LabVIEW, a programmable plug-in board for PCs featuring an FPGA and built-in analog and digital I/O provided consumers a way to integrate software algorithms into hardware. Since then, this technology has evolved and is currently being used in robust embedded hardware and system-level items of an industrial scale [28]. Software plays a crucial role in mechatronics and embedded systems of the future. Through offering a system-level view of various design factors and abstracting the complexities of the latest technologies, software tools empower engineers to develop high-performance systems to meet tomorrow's challenges. Kuru et al [29] reviewed and proposed the automation of everything as a transformation in advanced mechatronic systems within the industrial revolution. Hence, giving an insight of the interactions between the mechatronic system and the environment. Figure 4 shows the framework of advanced mechatronic system and its interaction with the environment. There are three major future trends in mechatronics which are ghost of computing, hidden life of data and future of fear. 


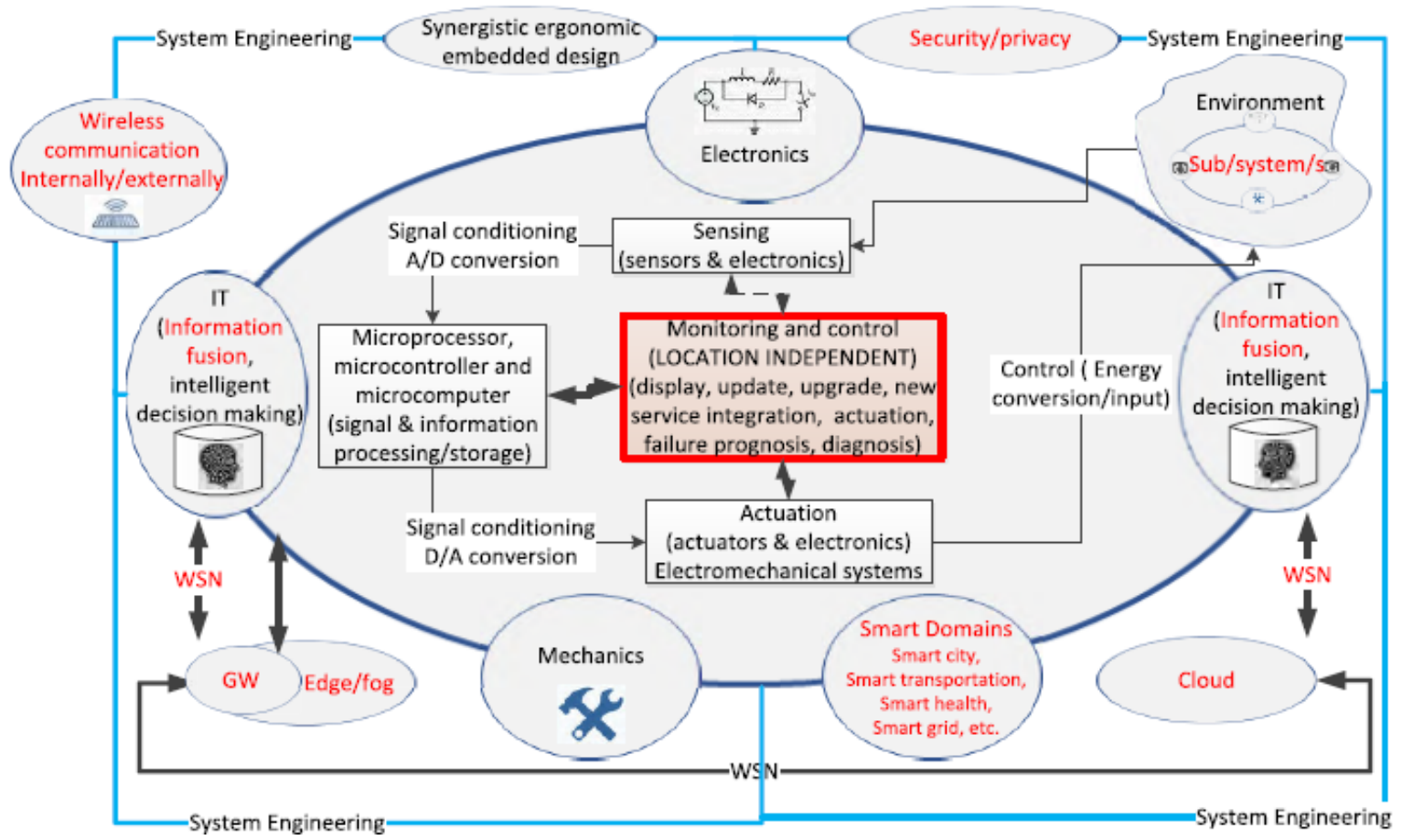

Figure 4. Advanced Mechatronic system and its interaction with the environment [29]

\subsection{Ghost of computing}

Ghost of Computing entails a decline in electronics capacity/size (miniaturization). When the size of the technology required for a computer is getting closer and closer to zero, the problem is no longer how much smaller and more powerful the technology can be produced, but what the technology can be used in now. Society is reaching a peak and turning point where there seem to be no end to limitations and mechatronic minds are able to realize every existence. Many development projects have for future mechatronic applications potential to bring mechatronic technologies to the wider and deeper regions. Microelectromechanical systems (MEMS) [30, 31], Nanotechnology [32, 33], bio-medical engineering [34], Nanoelectromechanical systems (NEMS) [35, 36], Nanomechatronics systems (NMS) [37] and optomechatronics [38] are the emerging fields under this category in mechatronics. These fields will certainly get to a point where devices will be in the smallest possible form, yet performing efficiently.

\subsection{Hidden life of data}

Hidden Life of Data refers to the use of big data and programming algorithms to understand the processes of human thinking which makes the data more efficient for us to use and, in a way, feels like it has its own mind. Data science [39-41] is a valuable skill and a necessary one. Engineers are making amazing inventions every day and the world of data science is filled with possibilities with the fairly recent emergence of robotics. Data science and robotics are important areas in which to keep an eye out. Robots are growing smarter and more advanced, but they've got quite a way to go before they really reach self-sufficiency. There is no way for customers, for example, to configure a robot to grasp every possible object that they may need to operate inside a household. Thankfully, developments in artificial intelligence (AI) may soon allow robots to find out for themselves this kind of basic task. Technology is moving forward and changing the way we do business and live in the world [42]. For example, researchers have created an AI-powered robot that can solve the puzzle autonomously, involving children inserting shaped pegs into the correct hole. The robot will solve the classic children's puzzle through a mechanism called Machine learning [43], a trial and error version of the automation. For instance, researchers may tell the robot to fit the square peg into the square hole and figure out how to do that. Big data technology [44] is leveraged by more than 53\% of the world's companies. This is a major jump from just $17 \%$ in 2015 . More companies are using data science technologies to streamline their processes and develop their organizational structures [45]. As a result, the exciting career prospects for data scientists are booming, this will synergize with sensor fusion, automation, machine learning and 5G [46-53], blockchain technology, internet and AI to yield a mind blowing and more advanced future. 


\subsection{Future of fear}

Future of fear is less of a new technology and more of a theory. The future of fear is about disabling the concerns people have about the future of technology. People create fears that they associate with technology's future but that aren't established in machines or IoT. After all, technology is, and has always been, an instrument that we are in charge of making human life more successful. Figure 4 depicts the future and trending synergies and births of mechatronics. Our entire modern world revolves around the electric advances society has made. Technological developments continue to evolve and develop in ways that are no longer visible by the scale of the technologies that we are developing, but by the creative ideas that we are able to bring into practice. Figure 5 reveals the original ideology of mechatronics together with current and emerging fields in mechatronics as a result of advancement in technology. Mechatronics is a field that opens the door to possibilities for new breakthrough ideas that can change everyday life. Although technology and the future have been envisaged in several different ways, the resources are given to futurists and tech companies to see what the world will look like in 10 or 15 years 'time, and of course more technological advances are coming.

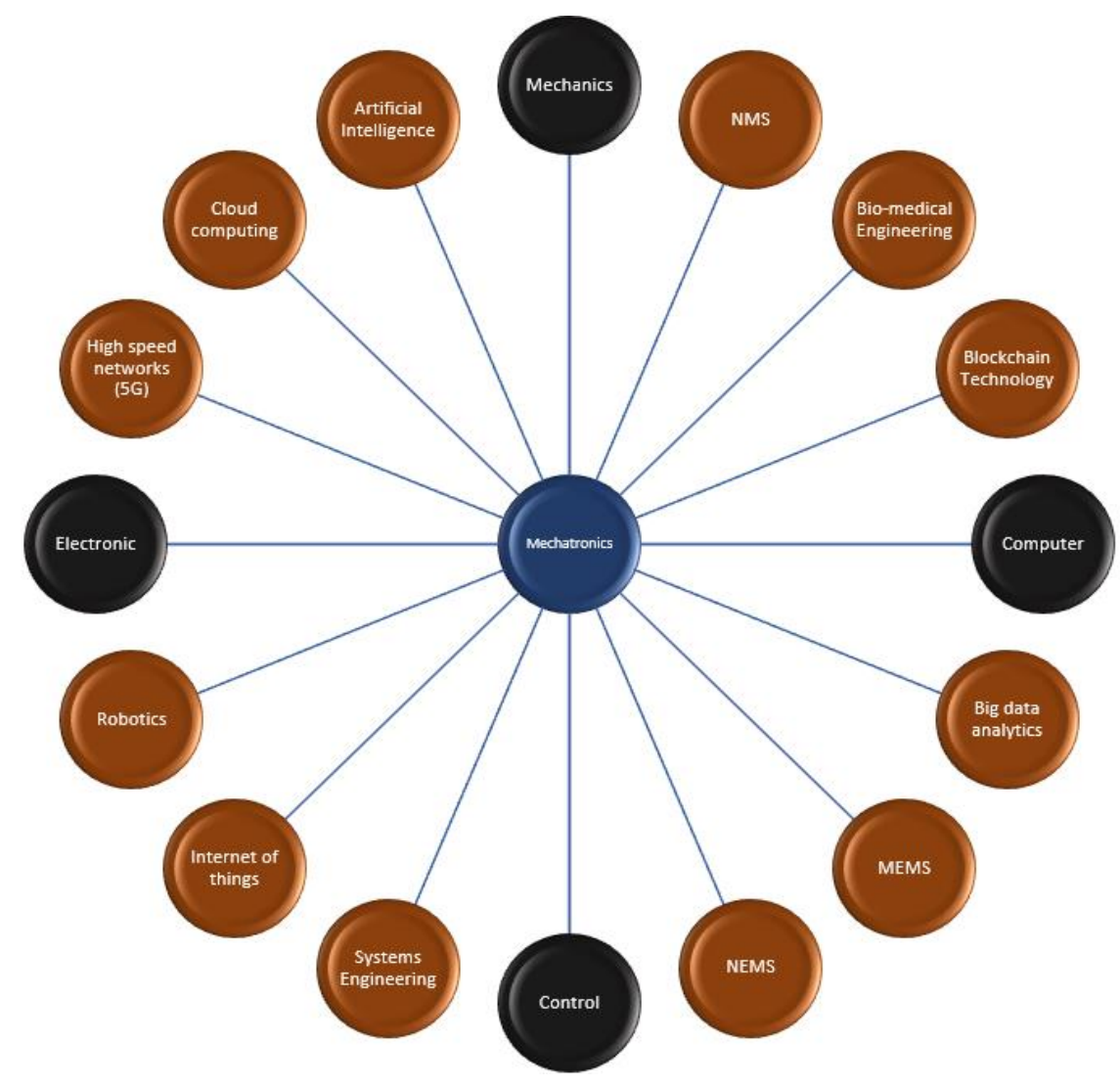

Figure 5. Current and future trends in mechatronics from the basic interdisciplinary synergy

\section{CONCLUSION}

This study has presented the future and emerging trends and technologies of mechatronics, which will create awareness of what to expect in the nearest future. Incorporation and integration of the highlighted technologies will yield a more robust system. Mechatronics will build several new pathways into an exciting future. Indeed, mechatronics opens up powerful technical possibilities that would never be possible through the adoption of a classic sub-system or conventional, single methods of discipline. Mechatronics describes the outcome of the process, and this insight of course lends itself to the concept of total quality. Technological advances change all branches of industry and affect everyone. Data-science practitioners will succeed irrespective of their past career history. In addition, mechatronic technologies are enhancing the society's quality of life and transforming essential areas such as medicine. Today, developments of artificial intelligence and machine learning (ML) are revolutionizing the market environment, driven by the expertise of talented data scientists. Efficient mechatronic design will result in cost-effectiveness products which are 
extremely attractive to consumers. In contrast, products designed in the more traditional, sequential way appear old-fashioned, have limited capabilities and lack consumer appeal. Mechatronics supports broad areas of interdisciplinary expertise. Improving our way of life and the goods we use is not constrained by the common fields limits. With the ever-changing demands and requirements of a dynamic and complex world, to keep in tandem, technologies and inventions have to progress at a very fast pace. In the nearesst future, mechatronics will play a major role in enhancing the reliability, protection and affordability of products. Future research will look into the negative effects of these technologies and necessary solutions to mitigate the threats.

\section{REFERENCES}

[1] F. Harashima, M. Tomizuka and T. Fukuda, "Mechatronics, "What Is It, Why, and How?," IEEE/ASME Transactions on Mechatronics, vol. 1, no. 1, pp. 1-4, March 1996, doi: 10.1109/TMECH.1996.7827930.

[2] R. Isermann, "Mechatronische Systeme Grundlagen," Springer Verlag, Berlin, Nov. 2007.

[3] G. S. Hegde, "Mechatronics (Engineering)," Jones and Bartlett, Jones \& Bartlett Learning, U K London, 2009.

[4] A. B. Fotso and A. Rettberg, "State of the art for mechatronic design concepts," Proceedings of 2012 IEEE/ASME 8th IEEE/ASME International Conference on Mechatronic and Embedded Systems and Applications, 2012, pp. 232-240, doi: 10.1109/MESA.2012.6275567.

[5] M. J. Kaur and P. Maheshwari, "Building smart cities applications using IoT and cloud-based architectures," 2016 International Conference on Industrial Informatics and Computer Systems CIICS, 2016, pp. 1-5, doi: 10.1109/ICCSII.2016.7462433.

[6] A. Kuttan, "Introduction to Mechatronics," Oxford University Press, New Delhi, India: 2007.

[7] O. Jaradat, I. Sljivo, I. Habli and R. Hawkins, "Challenges of Safety Assurance for Industry 4.0," 2017 13th European Dependable Computing Conference (EDCC), Geneva, 2017, pp. 103-106, doi: 10.1109/EDCC.2017.21.

[8] C. T. Nnodim, A. M. R. Fath El-Bab, B. W. Ikua, and D. N. Sila, "Design and simulation of a tactile sensor for fruit ripeness detection," Lecture Notes in Engineering and Computer Science: World Congress on Engineering and Computer Science 2019, pp. 390-395, 2019.

[9] C. Detweiler, M. Doniec, I. Vasilescu and D. Rus, "autonomous depth adjustment for underwater sensor networks: design and applications," IEEE/ASME Transactions on Mechatronics, vol. 17, no. 1, pp. 16-24, Feb. 2012, doi: 10.1109/TMECH.2011.2175003.

[10] N. K. Suryadevara, S. C. Mukhopadhyay, S. D. T. Kelly and S. P. S. Gill, "WSN-based smart sensors and actuator for power management in intelligent buildings," IEEE/ASME Transactions on Mechatronics, vol. 20, no. 2, pp. 564-571, Apr. 2015, doi: 10.1109/TMECH.2014.2301716.

[11] H. Hur and H. Ahn, "Unknown input observer-based filterings for mobile pedestrian localization using wireless sensor networks," IEEE Sensors Journal, vol. 14, no. 8, pp. 2590-2600, Aug. 2014, doi: 10.1109/JSEN.2014.2312193.

[12] X. Zhou, Z. Beilei, and G. Guohao, "Control parameters optimization based on co-simulation of a mechatronic system for an UA-based two-axis inertially stabilized platform,” Sensors, vol. 15, no. 8, pp 20169-20192, Aug 2015.

[13] J. Ma, S. L. Chen, C. S. Teo, A. Tay, A. Al Mamun, and K. K. Tan, "Parameter space optimization towards integrated mechatronic design for uncertain systems with generalized feedback constraints," Automatica, vol. 105, pp.149-158, 2019.

[14] I. Parvez, A. Rahmati, I. Guvenc, A. I. Sarwat and H. Dai, "A survey on low latency towards 5G: RAN, core network and caching solutions," IEEE Communications Surveys \& Tutorials, vol. 20, no. 4, pp. 3098-3130, Fourthquarter 2018, doi: 10.1109/COMST.2018.2841349.

[15] F. Boccardi, R. W. Heath, A. Lozano, T. L. Marzetta and P. Popovski, "Five disruptive technology directions for 5G," IEEE Communications Magazine, vol. 52, no. 2, pp. 74-80, Feb. 2014, doi: 10.1109/MCOM.2014.6736746.

[16] A. Gupta and R. K. Jha, "A Survey of 5G Network: Architecture and Emerging Technologies," IEEE Access, vol. 3, pp. 1206-1232, 2015, doi: 10.1109/ACCESS.2015.2461602.

[17] R. D. Schraft, "Mechatronics and robotics for service applications," IEEE Robotics \& Automation Magazine, vol. 1, no. 4, pp. 31-35, Dec. 1994.

[18] H. Komoto, and T. Tetsuo, "A framework for computer-aided conceptual design and its application tosystem architecting of mechatronics products," Computer-Aided Design, vol. 44, no. 10, pp 931-946, Feb. 2012.

[19] Y. Ai, M. Peng, and K. Zhang, "Edge computing technologies for internet of things: A primer," Digital Communication and Network, vol. 4, no. 2, pp. 77-86, 2018.

[20] A. M. Madni, C. C. Madni, and S. D. Lucero, "Leveraging digital twin technology in model-based systems engineering," Systems, vol. 7, no. 1, pp. 1-13, Jul 2019.

[21] M. Matar, H. Osman, M. Georgy, A. Abou-Zeid, M. El-Said, “A systems engineering approach for realizing sustainability in infrastructure projects," HBRC journal, vol. 13 no.2, pp 190-201, 2017.

[22] Z. Sheng, C. Mahapatra, C. Zhu and V. C. M. Leung, "Recent advances in industrial wireless sensor networks toward efficient management in IoT," in IEEE Access, vol. 3, pp. 622-637, 2015.

[23] M. Chiang and T. Zhang, "Fog and IoT: An overview of research opportunities," in IEEE Internet of Things Journal, vol. 3, no. 6, pp. 854-864, Dec 2016.

[24] J. Delsing, "Local cloud internet of things automation: Technology and business model features of distributed internet of things automation solutions," in IEEE Industrial Electronics Magazine, vol. 11, no. 4, pp. 8-21, 2017.

IAES Int J Rob \& Autom, Vol. 10, No. 1, March 2021:24-31 
[25] V. Gattulli, E. Ottaviano, and A. Pelliccio, "Mechatronics in the process of cultural heritage and civil infrastructure management," in Title: Intelligent Systems, Control and Automation: Science and Engineering, vol. 92, pp. 1-31, Springer International publishing AG, 2018.

[26] T. V. Santhosh, V. Gopika, A. K. Ghosh, and B. G. Fernandes, "An approach for reliability prediction of instrumentation \& control cables by artificial neural networks and Weibull theory for probabilistic safety assessment of NPPs," Reliability Engineering \& System Safety, vol. 170, pp. 31-44, Feb 2018.

[27] P. St. Onge, L. A. Temme, A. McAtee, K. J. O’Brien, B. K. Byrd, "Evaluation of the commercial, offthe-shelf (COTS) King-Devick eye tracking system," Defence Technical Information Center, vol. 184, no. 1, Pp. 571-578, 2019, doi: 10.1093/milmed/usy380.

[28] Z. Hajduk, "High accuracy FPGA activation function implementation for neural networks," Neurocomputing, vol. 247, pp. 59-61, 2017.

[29] K. Kuru and H. Yetgin, "Transformation to advanced mechatronics systems within new industrial revolution: A novel framework in automation of everything (AoE)," in IEEE Access, vol. 7, pp. 41395-41415, 2019.

[30] H. Zhang, F. Marty, X. Xia, Y. Zi, T. Bourouina, D. Galayko, P. Basset, "Employing a MEMS plasma switch for conditioning high-voltage kinetic energy harvesters," Nature communications, vol. 11, no. 1, pp. 1-10, Jun 2020.

[31] A. Setiono, M. Bertke, W. Nyang'au, J. Xu, M. Fahrbach, I. Kirsch, E. Uhde, A. Deutschinger, E. J. Fantner, C. H.Schwalb, H. S.Wasisto, "In-plane and out-of-plane MEMS piezoresistive cantilever sensors for nanoparticle mass detection," Sensors, vol. 20, no. 3, pp. 1-17, 2020.

[32] S. B. Arkadii Z. Victor, "Scientific and methodological aspects in mechatronics," Materials Science Power Engineering, vol. 107, no.1, pp. 134-142, 2019.

[33] J. C. Negrete, "Nanotechnology an Option in Mexican Agriculture," Journal of Biotechnology \& Bioinformatics Research. vol. 2, no. 2, pp. 1-3, 2020.

[34] S. Najarian, J. Dargahi, G. Darbemamieh, and S. H. Farkoush, "Mechatronics in medicine a biomedical engineering approach," McGraw-Hill Education, 2011.

[35] A. Lal, S. Ardanuc, J. T. Hoople, J. C. Kuo, "Computation devices and artificial neurons based on nanoelectromechanical systems," United States patent, Feb 2019.

[36] R. Maity, N. P. Maity and S. Baishya, "An efficient model of nanoelectromechanical systems based ultrasonic sensor with fringing field effects," in IEEE Sensors Journal, vol. 20, no. 4, pp. 1746-1753, 15 Feb 15, 2020.

[37] S. M. Afonin, "Structural-parametric model multilayer electromagnetoelastic actuator for nanomechatronics," International Journal of Physics, vol. 7, no.2, pp. 50- 57 Aug 2019.

[38] T. H.Sun, Z. Jia, J. Ge, R. Sha, Y. Xie, Y. Gu, "The multifunctional safety helmet for coal miners of the optomechatronics," European International Journal of Science and Technology, vol. 8, no. 11, pp. 64-77, Dec. 2019.

[39] A. Charfi et al, "Possibilistic similarity measures for data science and machine learning applications," in IEEE Access, vol. 8, pp. 49198-49211, 2020

[40] P. C. Okolie, E. C. Nwadike, J. L. Chukwuneke, and C. T. Nnodim, "The analysis of cigarate production using double exponential smoothing model," Academic Journal of Science, vol.7, no.2, pp. 293-308, Feb. 2017.

[41] H. Alamleh, Ali Abdullah S. AlQahtani, "A weighting system to build physical layer measurements maps by crowdsourcing data from smartphones," International Journal of Robotics and Automation IJRA, vol. 9, no. 3, pp. 211-219, Sep 2020.

[42] W. Guo, "Explainable artificial intelligence for 6G: Improving trust between human and machine," in IEEE Communications Magazine, vol. 58, no. 6, pp. 39-45, June 2020.

[43] G. Zhu, D. Liu, Y. Du, C. You, J. Zhang and K. Huang, "Toward an intelligent edge: Wireless communication meets machine learning," in IEEE Communications Magazine, vol. 58, no. 1, pp. 19-25, Jan. 2020.

[44] X. Wang, et al., "ADTT: A highly efficient distributed tensor-train decomposition method for IIoT big data," in IEEE Transactions on Industrial Informatics, vol. 17, no. 3, pp. 1573-1582, Mar. 2021.

[45] C. T. Nnodim, A. M. R. Fath El-Bab, B. W. Ikua, and D. N. Sila, "Estimation of the modulus of elasticity of mango for fruit sorting," International Journal of Mechanical and Mechatronics Engineering, vol. 9, no. 2, pp. 1-10, 2019.

[46] S. O. Nosakhale, et al., "Optimal sizing and analysis of a hybrid energy system for a community microgrid in Nigeria," Journal of Engineering and Applied Sciences, vol. 14, no. 23, pp. 8769-8778, 2019.

[47] M. Salawu, et al., "A chi-square-SVM based pedagogical rule extraction method for microarray data analysis," International Journal of Advances in Applied Sciences, vol. 9, no. 2, pp. 1-10, 2020.

[48] S. O. Abdulsalam et al., "Customer churn prediction in banking industry using K- Means and support vector machine algorithms," International Journal of Multidisciplinary Sciences and Advanced Technology, vol. 1, no. 1, pp. 60-68, 2020.

[49] M. O. Arowolo, M. O. Adebiyi, A. A. Adebiyi and O. J. Okesola, "A hybrid heuristic dimensionality reduction methods for classifying malaria vector gene expression data," in IEEE Access, vol. 8, pp. 182422-182430, 2020.

[50] A. O. Onokwai, U. C. Okonkwo, C. O. Osueke, T.M.A. Olayanju, C. A Ezugwu, R. S. Diarah, S. O. Banjo, E. Onokpite, T. S. Olabamiji, M. Ibiwoye, J. A. James, T. C. Nnodim, "Thermal analysis of solar box cooker in OmuAran Metropolis.” Journal of Physics: Conference Series, vol. 1378, no. 3, pp. 1-20, 1378, 1-20.

[51] A. A. Ajani, et al., "GPON and V-Band $\mathrm{mm}$ wave in green backhaul solution for 5G ultra-dense network," International Journal of Electrical and Computer Engineering IJECE, vol. 11, no. 1, pp. 101-112, Jun 2020.

[52] C. T. Nnodim, A. M. R. Fath El-Bab, B.W. Ikua, D. N. Sila, "Design, Simulation, and Experimental Testing of a Tactile Sensor for Fruit Ripeness Detection," Transactions on Engineering Technologies, pp. 59-73, 2021.

[53] S.O. Abdulsalam et al., "Performance evaluation of ANOVA and RFE algorithms for classifying microarray dataset using SVM," Lecture Notes in Business Information Processing, vol 402, pp. 480-492, 2020. 